\title{
Correction to: Long-term outcomes of ilio-sacral screws in minimally invasive bipolar fusionless technique for neuromuscular scoliosis: a retrospective study in 167 patients
}

\author{
Mathilde Gaume ${ }^{1} \mathbb{D} \cdot$ Philippe Gerard $^{1} \cdot$ Nejib Khouri ${ }^{1} \cdot$ Christophe Glorion $^{1} \cdot$ Jean Dubousset ${ }^{2} \cdot$ Lotfi Miladi $^{1}$
}

Published online: 9 February 2022

๑) Springer-Verlag GmbH Germany, part of Springer Nature 2022

Correction to: Archives of Orthopaedic and Trauma Surgery
https://doi.org/10.1007/s00402-021-04332-x

The original version of this article unfortunately contained a mistake. Author name Philippe Gerard was incorrectly written as Pierre Gerard.

Publisher's Note Springer Nature remains neutral with regard to jurisdictional claims in published maps and institutional affiliations.

The original article can be found online at https://doi.org/10.1007/ s00402-021-04332-x.

Lotfi Miladi

1.miladi@aphp.fr

1 Pediatric Orthopedic Surgery Department, Paris Descartes University, Assistance Publique Hôpitaux de Paris (AP-

HP),Necker Hospital, 149 rue de Sevres, 75015 Paris, France

2 French National Academy of Medicine, Paris, France 